\title{
Corrosion Behaviour of TiC Particle-reinforced 304 Stainless Steel in Simulated Marine Environment at $650^{\circ} \mathrm{C}$
}

\author{
Qianlin $W U,{ }^{1) *}$ Yang $X U,{ }^{1)}$ Jianqiang ZHANG ${ }^{21}$ Ning $Z \mathrm{ZHONG}^{1)}$ Chunhua FAN, ${ }^{1)}$ Xueting $\mathrm{CHANG}^{1)}$ and \\ Xiqin $\mathrm{ZHANG}^{1)}$ \\ 1) College of Ocean Science and Engineering, Shanghai Maritime University, Shanghai, 201306 China. \\ 2) School of Materials Science and Engineering, University of New South Wales, Sydney, NSW 2052 Australia.
}

(Received on August 17, 2018; accepted on October 5, 2018)

\begin{abstract}
Corrosion behaviour of 304SS and TiC-reinforced 304SS in simulated marine environment at $650^{\circ} \mathrm{C}$, compared with that of 304SS in air, has been investigated. The corrosion of 304SS in marine environment is more severe than that in air due to the effect of $\mathrm{NaCl}$ and water vapor. For TiC-304SS, a finer microstructure and higher dislocation density formed by $\mathrm{TiC}$ addition accelerates chromium diffusion. The formation of $\mathrm{TiO}_{2}$ by the oxidation of $\mathrm{TiC}$ possibly assists chromia nucleation and increases the adhesion of chromia scale. As a result, corrosion resistance is increased. However, the corrosion rate of 304SS-6TiC is faster than that of 304SS-2TiC and the possible reason to cause this is discussed.
\end{abstract}

KEY WORDS: TiC; 304stainless steel; cyclic oxidation; NaCl deposit; water vapor.

\section{Introduction}

With the development of military field, water traffic and ocean industry, marine corrosion has drawn more and more attention by scientists and steel industries. Many hightemperature parts of naval aircrafts, ships or offshore platform, such as return piping, steam piping, heater exchanger piping and the hot-end of exhaust system, are exposed to the marine environment where salty fog and high humidity are concentrated during their parking time in marine environments. It means that these high-temperature parts will suffer electrochemical corrosion at room temperature during their parking time. At actual working time, salts (e.g. $\mathrm{NaCl}$ ) accumulated on the surface of the units, could result in $\mathrm{NaCl}$-induced corrosion at high temperature, forming corrosion scales. Also the high concentration of moisture obtained in marine environment will affect the corrosion process of steels at high temperature during the working time. Therefore, the actual working environment is a combination of solid $\mathrm{NaCl}$ and water vapor. In addition, when turbine engines work in marine environments, salt from the atmosphere accumulates on turbine blades and the moist air with enough water vapor is assimilated in the machines at the same time, resulting in corrosion caused by both deposited salt and water vapor. ${ }^{1)}$

It is well known that the oxidation resistance of alloy can be remarkably deteriorated by the addition of $\mathrm{NaCl}^{2,3}$ ) or water vapor ${ }^{4,5)}$ in air at high temperature. Therefore, in order to develop high corrosion-resistant alloys in marine environment, extensive studies have been conducted on

\footnotetext{
* Corresponding author: E-mail: wq1_1978@163.com

DOI: https://doi.org/10.2355/isijinternational.ISIJINT-2018-534
}

investigating the corrosion mechanism of pure $\mathrm{Fe},{ }^{6)} \mathrm{Fe}-\mathrm{Cr}$, ${ }^{7}$ pure $\mathrm{Cr},{ }^{8)} 1 \mathrm{Cr} 11 \mathrm{NiW} 2 \mathrm{MoV}^{9)}$ and Ti60 ${ }^{10)}$ alloys with solid $\mathrm{NaCl}$ deposits in water vapor at $500-700^{\circ} \mathrm{C}$. Surface coatings of $\mathrm{Ni}_{3}(\mathrm{AlCr}),{ }^{11)} \mathrm{K} 38 \mathrm{G}^{12)}$ and $\mathrm{Ni}-\mathrm{Si}^{13)}$ alloys have also been used to improve oxidation resistance of these alloys in marine environment.

TiC has been widely used as reinforcement for steels because of its desirable characteristics, such as its high elastic modulus, high melting point and excellent wettability with steels. ${ }^{14,15)}$ In recent years, oxidation behaviour of TiC-containing steels has been investigated. ${ }^{16,17)}$ According to these results, the oxidation resistance of steels in air can be remarkably improved by $\mathrm{TiC}$ addition in the steel. It is therefore reasonable that the addition of $\mathrm{TiC}$ in steel can improve the oxidation resistance in marine environment. The 304 stainless steel (304SS) is well known for its excellent creep-rupture strength and oxidation resistance at high temperature. It is widely applied as high temperature structural materials in turbine engine components and other industrial parts in marine environments. TiC-304SS was successfully fabricated in this work. At present, little attention has been given to the effect of $\mathrm{TiC}$ on oxidation behavior of steels in marine environment.

In the present study, a detailed investigation has been undertaken to understand the role of TiC particles on oxidation behavior of $304 \mathrm{SS}$ by kinetic investigation and microstructure analysis, and this investigation can provide some valuable information to utilize the TiC-304SS in marine environment.

\section{Experimental Procedures}

To investigate the influence of different levels of $\mathrm{TiC}$ 
on the corrosion resistance of the 304SS in marine environments, $\mathrm{TiC}$ of $2 \%$ and $6 \%$ (in weight percentage) was introduced to 304SS. The composition of 304SS is listed in Table 1. A detailed procedure to obtain TiC-304SS is described elsewhere ${ }^{15,16)}$ and a basic procedure is summarized below. TiC was introduced to $304 \mathrm{SS}$ by adding preformed blocks of titanium, carbon and iron powders into the melt in a vacuum medium frequency induction melting furnace, and then the obtained ingots were remelted by electroslag melting into $120 \mathrm{~mm}$ diameter ingots. Finally, the ingots were forged, heat-treated and cut into rectangular coupons, $15 \times 10 \times 2.0 \mathrm{~mm}$.

Cyclic reactions were applied in the corrosion tests. Each cycle contained four steps. Firstly, a specimen was put inside an $\mathrm{Al}_{2} \mathrm{O}_{3}$ crucible and total weight was measured. Then the sample was completely immersed in $3.5 \mathrm{wt} . \%$ $\mathrm{NaCl}$ solution for $1 \mathrm{~h}$ at room temperature in the crucible. Secondly, the $\mathrm{NaCl}$ solution was removed by using syringes, and then the crucible with specimen was introduced in the furnace at $650^{\circ} \mathrm{C}$ for $10 \mathrm{~h}$. After that, the crucible was taken out of the furnace, cooled to room temperature in air and weighted. Lastly, the corroded samples were carefully taken out of crucibles and weighted to get the weight change excluding spalled oxide. The corroded sample was replaced

Table 1. Chemical composition of 304 stainless steel (wt $\%$ ).

\begin{tabular}{ccccccccc}
\hline Steel & $\mathrm{C}$ & $\mathrm{Si}$ & $\mathrm{Mn}$ & $\mathrm{S}$ & $\mathrm{P}$ & $\mathrm{Cr}$ & $\mathrm{Ni}$ & $\mathrm{Fe}$ \\
\hline $304 \mathrm{SS}$ & $<0.07$ & $<1$ & $<2$ & $<0.030$ & $<0.045$ & $18-20$ & $8-10.5$ & Bal. \\
\hline
\end{tabular}
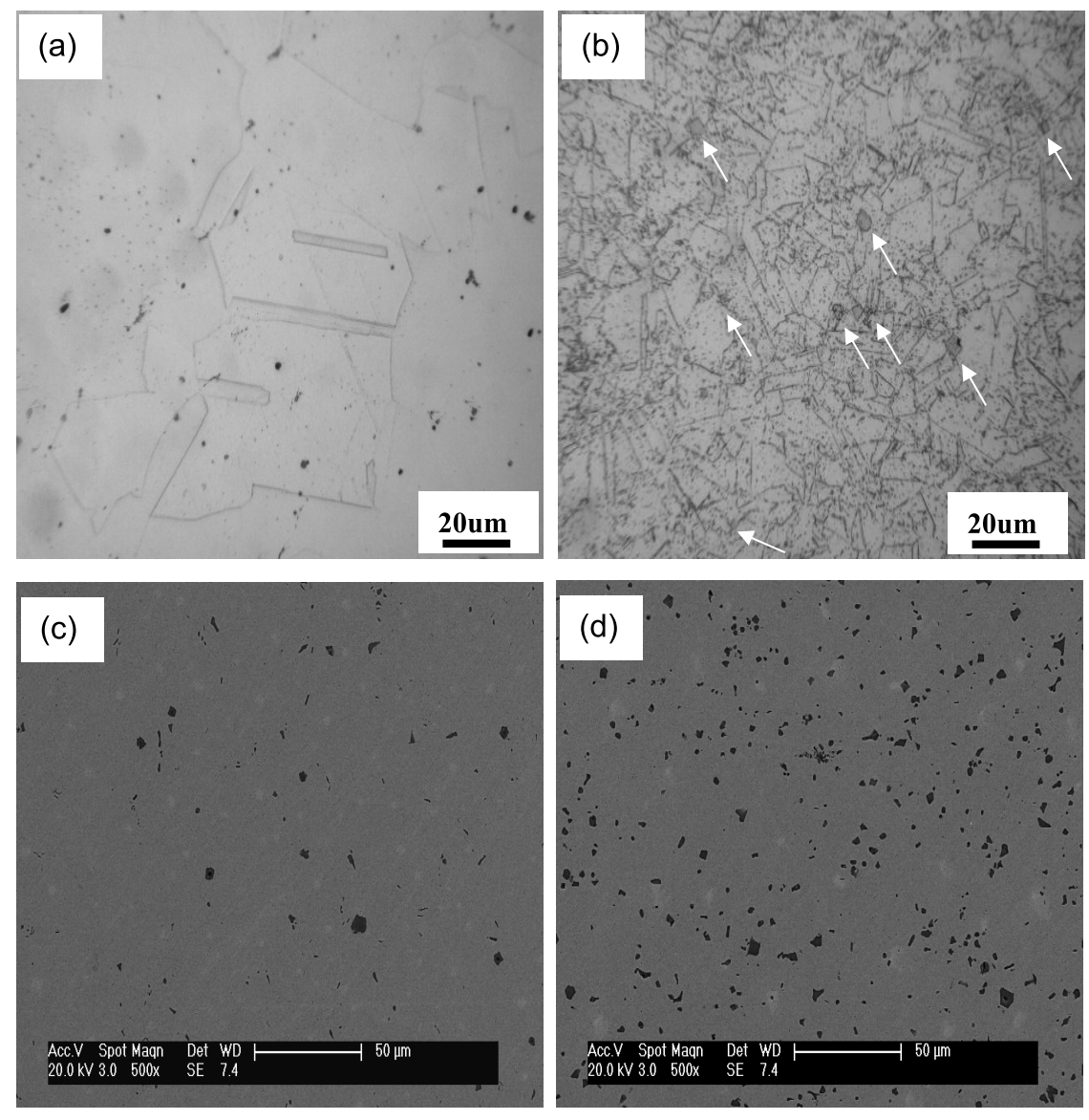

Fig. 2. Microstructure of the steels studied: (a) 304SS; (b)-(c) 304SS-2TiC; (d) 304SS-6TiC.

back in the crucible for next cycle reaction by repeating above procedures of immersing in $\mathrm{NaCl}$ solution, reacting in furnace and measuring the weight change. Schematic diagram of each cycle is shown in Fig. 1. Same experiments were repeated three times. Average mass changes per unit area were plotted as a function of cyclic times. The purpose of cyclic tests was to create severe conditions, which simulates the working conditions for the alloys. In order to compare the effect of $\mathrm{NaCl}$ and water vapor on the alloys, $304 \mathrm{SS}$ reacted in only air without $\mathrm{NaCl}$ and water vapor was also conducted.

After reaction, surface morphologies and corrosion products were examined using scanning electron microscope (SEM) equipped with energy-dispersive X-ray spectroscope (EDX). The reaction products were characterized using $\mathrm{X}$-ray diffraction (XRD) to identify corrosion phases.

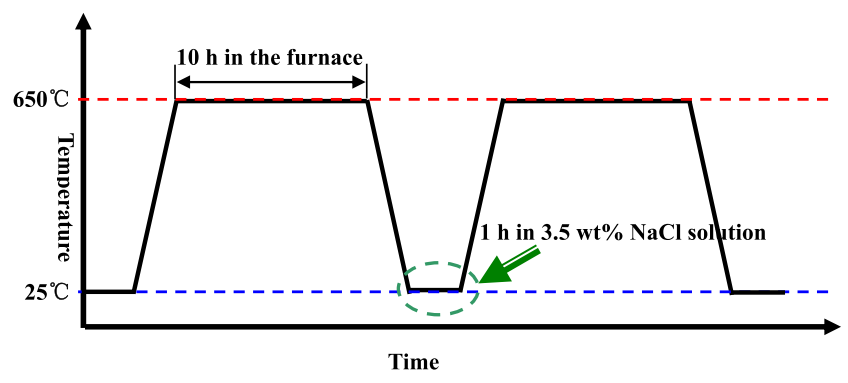

Fig. 1. Cyclic oxidation test conditions. (Online version in color.) 


\section{Results}

\subsection{Microstructure of Alloys before Reaction}

Figure 2 presents the microstructures of specimens. The microstructure of 304SS consisted of large twins and austenitic matrix (see Fig. 2(a)), while TiC-304SS consisted of fine austenitic matrix and TiC particles (arrowed in Fig. 2(b)) and small Cr-rich carbides with relatively dark contrast distributed uniformly in the microstructure (Fig. 2(b)). The chromium carbide observed was a byproduct of SHS reaction due to the existence of carbon in the melt, which was brought by the preformed blocks during melting of 304SS. Unentched samples of 304SS-2TiC and 304SS-6TiC were examined by SEM. Figures 2(c) and 2(d) show the distribution, morphology and size of $\mathrm{TiC}$ particles with relatively dark contrast in 304SS-2TiC and 304SS-6TiC, respectively. Most of the TiC particles had a faceted and spherical morphology and were uniformly dispersed in both alloys. The particle size of $\mathrm{TiC}$ was in the range $0.1-10 \mu \mathrm{m}$, more or less uniformly dispersed. Clearly, more $\mathrm{TiC}$ was present in 304SS-6TiC than 304SS-2TiC. A detailed description of microstructures of the alloys studied was reported in the previous papers. $^{15,16)}$

\subsection{Cyclic Corrosion Kinetics}

Weight changes with spalled oxide during cyclic corrosion were compared between air and simulated marine environment in Fig. 3(a). 304SS exhibited superior oxidation resistance in air and maintained a low oxidation rate in the whole reaction time investigated, while all samples showed a high corrosion rate in simulated marine environment. After 20 cycles, weight gain with spalled oxide of $304 \mathrm{SS}$ in simulated marine environment $\left(\sim 19.86 \mathrm{mg} / \mathrm{cm}^{2}\right)$ was 15 times higher than that of $304 \mathrm{SS}\left(\sim 1.27 \mathrm{mg} / \mathrm{cm}^{2}\right)$ in air. This indicates that the corrosion of 304SS in marine environments was more serious than that in inland areas. 304SS behaved protectively in air, but suffered breakaway corrosion in simulated marine environment during the whole reaction time. Evidently, the addition of $\mathrm{TiC}$ in $304 \mathrm{SS}$ had significantly improved the breakaway corrosion and corrosion resistance. Despite initial period of rapid reaction in simulated marine environment, 304SS-2TiC went into parabolic corrosion after about 2 cycles, and 4 cycles for 304SS-6TiC. Comparing two TiC adding steels, corrosion for $2 \% \mathrm{TiC}$ steels was faster than that of 304SS-6TiC before 10 cycles, but the trend started to reverse after 10 cycles, as shown in Fig. 3(a). The total mass gain with spalled oxide for 20 cycles was $1.27,19.86,15.27$ and $16.00 \mathrm{mg} / \mathrm{cm}^{2}$, for $304 \mathrm{SS}$ in air, 304SS, 304SS-2TiC and 304SS-6TiC in simulated marine environment, respectively.

Figure 3(b) compares the weight of spalled oxides recorded during cyclic corrosion. An apparent spallation was recorded for samples in the simulated marine environment, especially for 304SS. However, addition of $\mathrm{TiC}$ to 304SS resulted in a significant decrease of weight of spalled oxide, indicating the slight spallation during cyclic corrosion. Figure 3(c) shows the weight change without spalled oxide during cyclic corrosion. The corrosion information from Fig. 3(c) was consistent with that from Figs. 3(a), 3(b).
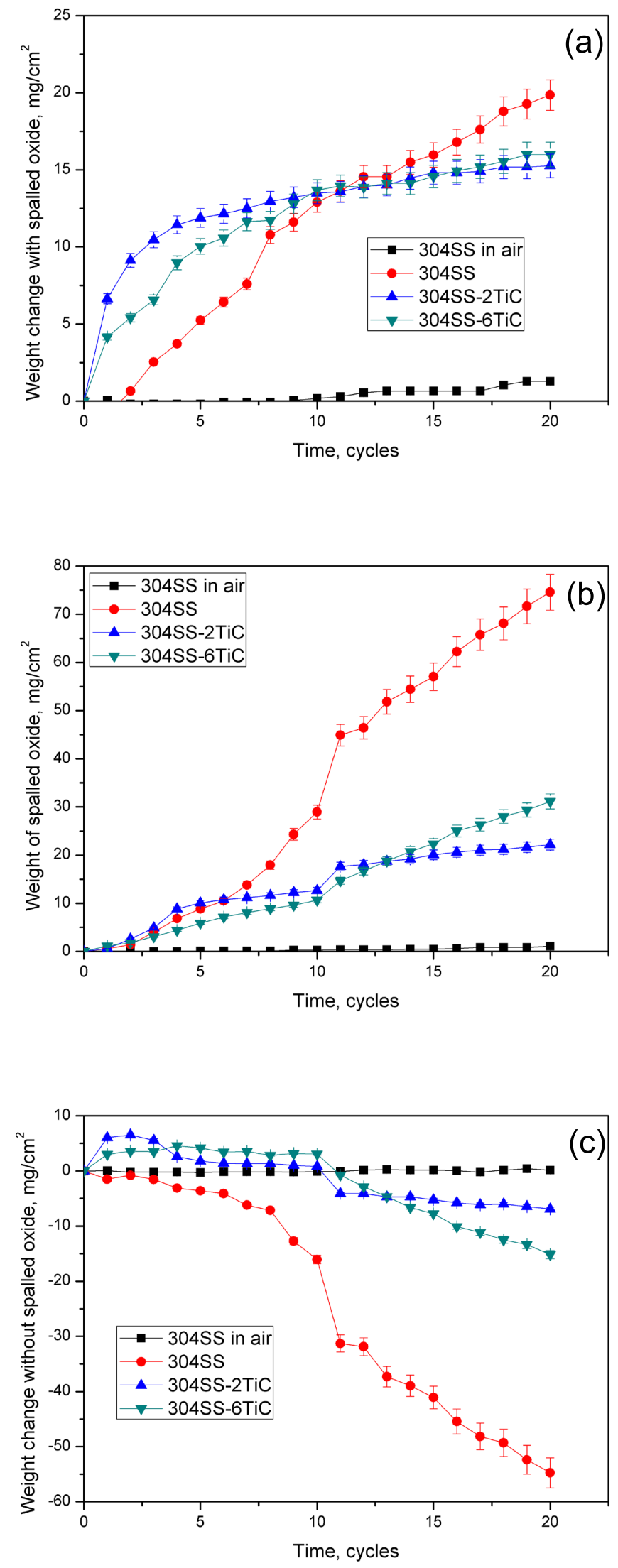

Fig. 3. Cyclic corrosion kinetics in air and simulated marine environment: (a) weight change with spalled oxide; (b) weight of spalled oxide; (c) weight change without spalled oxide. (Online version in color.)

3.3. Identification of the Phases in the Corrosion Layers XRD analysis was conducted to determine phases present in the surface corrosion layer. Figures 4(a)-4(c) shows the 

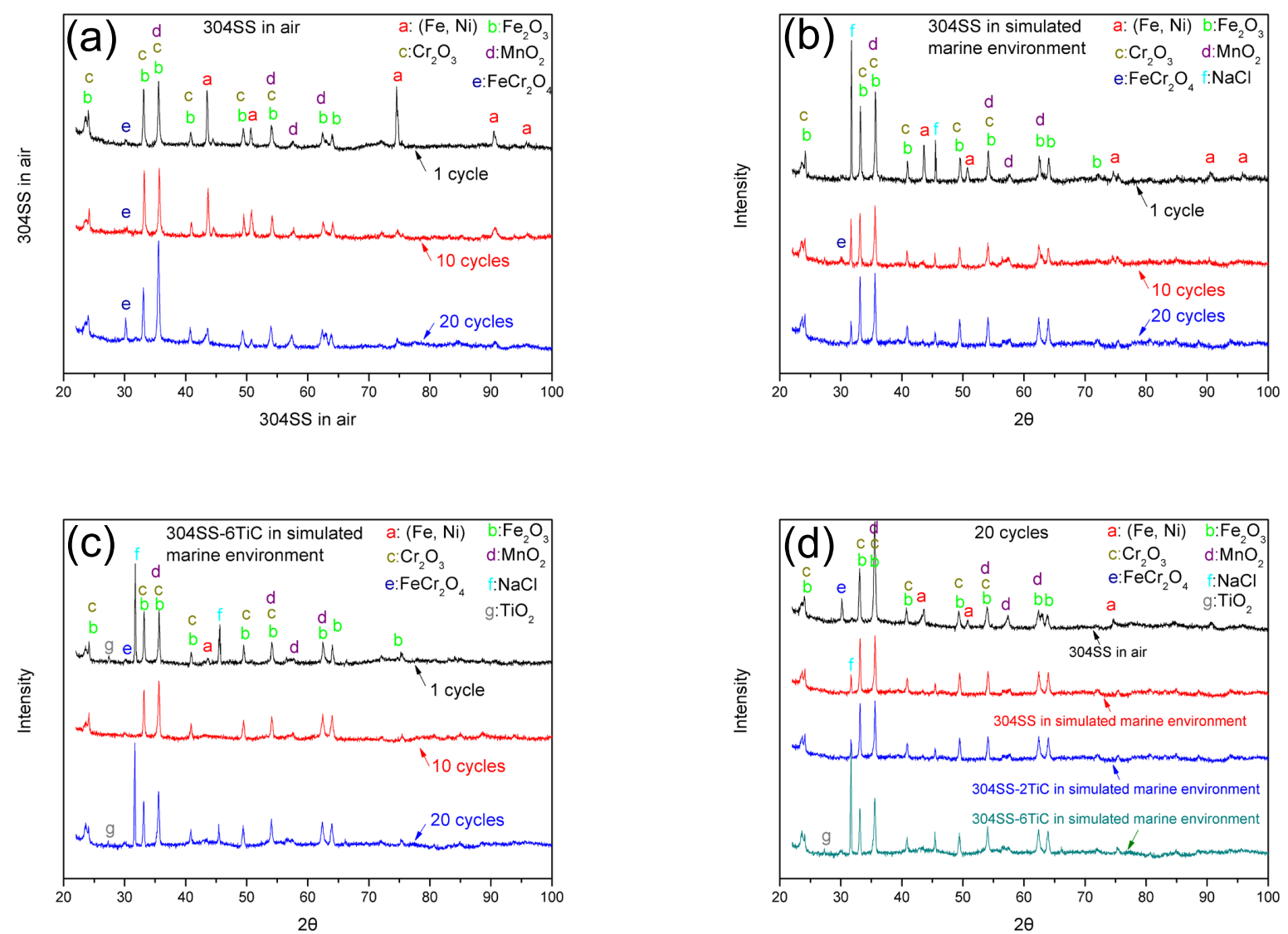

Fig. 4. XRD spectra for surface of (a) 304SS in air, (b) 304SS in simulated marine environment and (c) 304SS-6TiC in simulated marine environment after 1, 10, 20 cycles; (d) all samples after 20 cycles. (Online version in color.)

XRD pattern of corrosion layers for 304SS in air, 304SS and 304SS-6TiC in simulated marine environment after 1, 10, 20 cycles. The results revealed that the surface corrosion layers of all samples mainly composed of the $\mathrm{Fe}_{2} \mathrm{O}_{3}$ and $\mathrm{Cr}_{2} \mathrm{O}_{3}$ oxides. Compared with phases in the corrosion layers of two samples in simulated marine environment, obvious peaks of $\mathrm{Fe}-\mathrm{Cr}$ substrate and $\mathrm{FeCr}_{2} \mathrm{O}_{4}$ were detected in the XRD pattern of 304SS in air. As the corrosion time increases for all samples, the peak intensities of $\mathrm{Fe}-\mathrm{Cr}$ substrate decrease, corresponding to the increase in the thickness of oxides. For two samples in simulated marine environment, the $\mathrm{NaCl}$ peak was seen in the corrosion layers due to the solid $\mathrm{NaCl}$ deposit on the sample surfaces. For 304SS-6TiC sample, $\mathrm{TiO}_{2}$ was also found on the surface.

Figure 4(d) shows XRD patterns from the surface of corrosion layers of all tested samples in different environments after 20 cycles. Compared with 304SS in air, no obvious matrix information was found for all samples in simulated marine environment, indicating a thick corrosion layer formation in simulated marine environment. Meanwhile, the $\mathrm{FeCr}_{2} \mathrm{O}_{4}$ peak was not also detected for all samples in simulated marine environment, as comparison with 304SS in air. However, information on $\mathrm{Na}_{2} \mathrm{CrO}_{4}$ should be detected in the corrosion layer of $\mathrm{Fe}-\mathrm{Cr}$ steels in $\mathrm{NaCl}$ and/or water vapor environments according to the previous reports, ${ }^{18,19)}$ which is not in agreement with this research.

\subsection{Microstructure Investigation of Corrosion Layers}

The morphologies of corrosion layers were examined by SEM, as shown in Fig. 5. After 1 cycle, slight cracking and spalling were observed on the oxidation scale of 304SS in air, as shown in Fig. 5(a). However, the oxide formed in these locally spalling areas was smooth and dense (see insert in Fig. 5(a)). The oxide layer was identified to be iron/ chromium oxide by EDX analysis (see Fig. 5(i)). Increasing reaction time to 20 cycles, a smooth and dense oxide layer was still observed, as seen in Fig. 5(b).

For 304SS in simulated marine environment, the severe spalling was found on the corrosion layer (see Fig. 5(c)) and many large voids were shown in the spalled area (see insert in Fig. 5(c)). The chemical composition of the spalled area by EDX analysis was rich in $\mathrm{O}, \mathrm{Na}$ and $\mathrm{Cr}$ (see Fig. 5(j)), and suggested that the inner layer was probably composed of $\mathrm{Na}_{2} \mathrm{CrO}_{4}$ or combination of $\mathrm{Na}_{2} \mathrm{CrO}_{4}$ and $\mathrm{Cr}_{2} \mathrm{O}_{3}$. The outer layer was $\mathrm{Fe}_{2} \mathrm{O}_{3}$ according to XRD result and EDX analysis. The corrosion layer which bears large voids in the spalled area developed further to cover almost whole surface after 20 cycles (see Fig. 5(d)). Addition of TiC to 304SS resulted in the alleviation of the severe spalling phenomenon (see Figs. 5(c), 5(e) and 5(g)) and the decrease of the size of voids (see Figs. 5(d), 5(f) and 5(h)). Compared with 304SS-6TiC, the smaller voids and less spalling occurred for 304SS-2TiC. In addition, many solid $\mathrm{NaCl}$ particles were seen on the corrosion layers of samples in simulated marine environment. This information from the Fig. 5 was in agreement with the weight gain kinetics in Fig. 2.

Figure 6 displays cross-sections of 304SS in air and simulated marine environment after 20 cycles. A thin ( $\sim 6 \mathrm{um})$, dense and continuous oxide scale was closely attached to the surface for $304 \mathrm{SS}$ in air, while a thick ( $\sim 70 \mathrm{um})$ cor- 

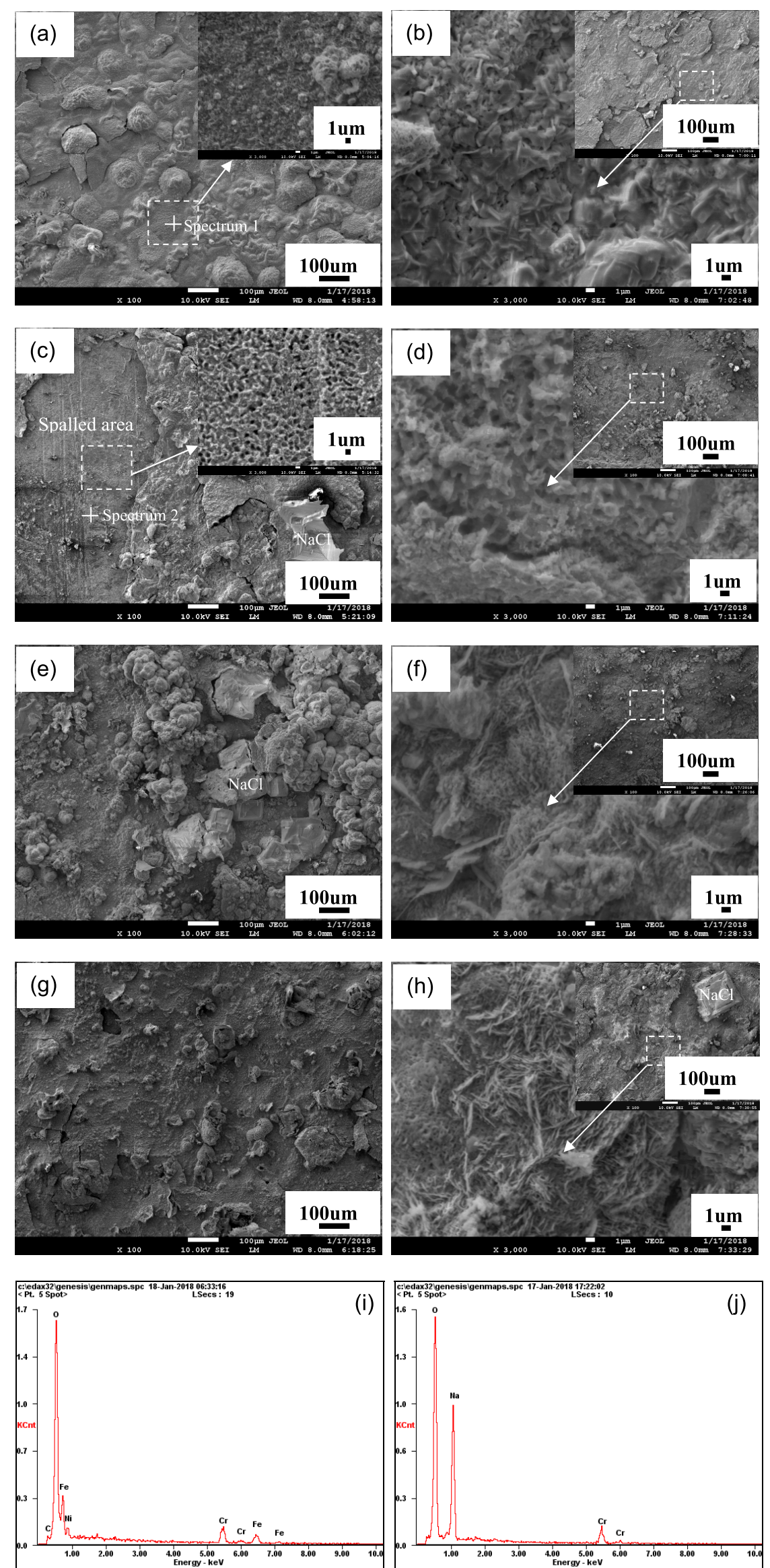

Fig. 5. Morphologies of oxide scales: (a)-(b) 304SS in air after 1 and 20 cycles oxidation, respectively; (c)-(d) 304SS in simulated marine environment after 1 and 20 cycles oxidation, respectively; (e)-(f) 304SS-2TiC in simulated marine environment after 1 and 20 cycles oxidation, respectively; (g)-(h) 304SS-6TiC in simulated marine environment after 1 and 20 cycles oxidation, respectively; (i)-(j) EDX from marked 1 in (a) and 2 in (c), respectively; Inserts in Fig. 5 (a and c) are high magnification images of he squared areas with dashed white lines; Inserts in Fig. 5 (b, d, f and g) are low magnification images of he squared areas with dashed red lines. (Online version in color.) 

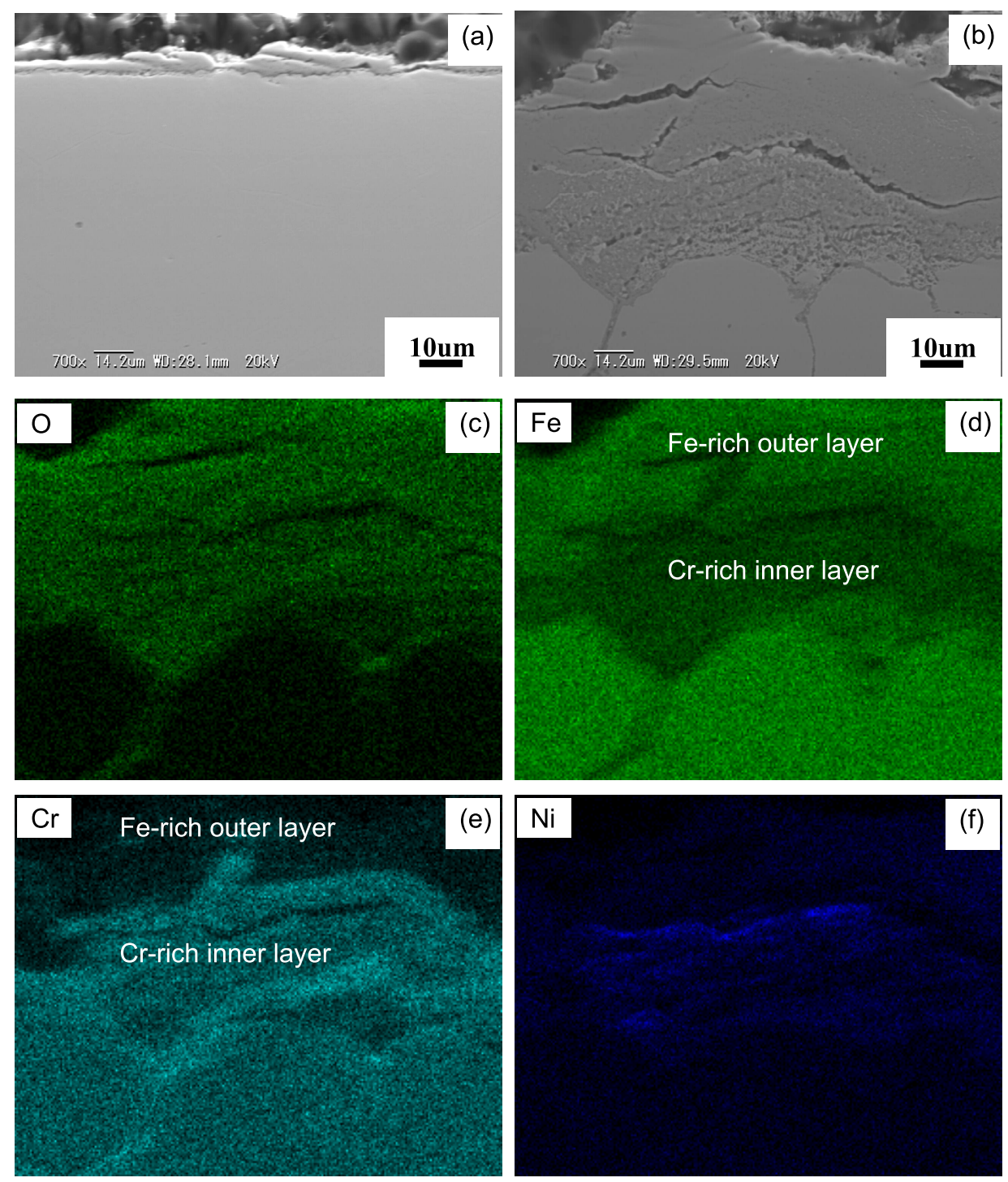

Fig. 6. SEM map-scanning of cross-sections of 304SS in air and simulated marine environment: (a) SEM morphology in air; (b) SEM morphology in simulated marine environment; (c)-(f) O, Fe, $\mathrm{Cr}$ and Ni elements in simulated marine environment, respectively. (Online version in color.)

rosion layer with many clear cracks and voids was formed on the surface of 304SS in simulated marine environment. Composition analysis by EDX showed that $\mathrm{O}, \mathrm{Cr}$, Fe elements were detected in the oxidation scale of 304SS in air. Therefore, the oxidation scale of 304SS in air mainly consisted of $\mathrm{Fe}_{2} \mathrm{O}_{3}, \mathrm{Cr}_{2} \mathrm{O}_{3}$ and $\mathrm{FeCr}_{2} \mathrm{O}_{4}$ phases according to EDX and XRD results, which was consistent with the previous reports. ${ }^{16)}$ Based on the diverse composition by EDX (see Figs. 6(b)-6(e)), the oxidation scale could be mainly divided into outer and inner layers, as indicated in Figs. 6(d) and 6(e). It is obvious that the outer layer was Fe-rich oxides, while the inner layer was $\mathrm{Cr}$-rich oxides. Severe intergranular oxidation was seen deep inside the substrate of 304SS in simulated marine environment, while intergranular oxide was not clearly found inside the substrate of 304SS in air. From detailed observation of Figs. 6(b) and 6(f), it is interesting that the cracks in the corrosion layer seemed to correspond to the Ni-rich oxides.

Figure 7(a) shows the cross-sectional morphologies of 304SS-6TiC in simulated marine environment after 20 cycles. Although many voids were also observed in the corrosion layer, no clear cracks were found. Based on composition analysis by EDX (see Figs. 7(b)-7(f)), the corrosion layer $(\sim 60 \mu \mathrm{m})$ mainly consisted of Fe-rich oxides in the outer layer and $\mathrm{Cr}$-rich oxides in the inner layer. Many fine Ti-rich particles were seen in the inner layer and steel substrate but not in the outer layer. This phenomenon could be due to the external diffusion of $\mathrm{Fe}$ which leads to the outer scale iron oxide scale where no Ti diffuses there.

\section{Discussion}

\subsection{Corrosion Behavior of 304SS in Simulated Marine Environment}

Oxidation behaviour of 304SS in air has been widely reported in the paper. ${ }^{16,20,21)} 304 \mathrm{SS}$ exhibits superior high temperature oxidation resistance, because the selective oxidation of chromium leads to the formation of a protective Cr-rich oxide layer that inhibits further oxidation reaction. However, in simulated marine environment, 304SS suffer severe corrosion. In the first cycle, all samples would firstly experience slightly electrochemical corrosion in $3.5 \mathrm{wt} \%$ 

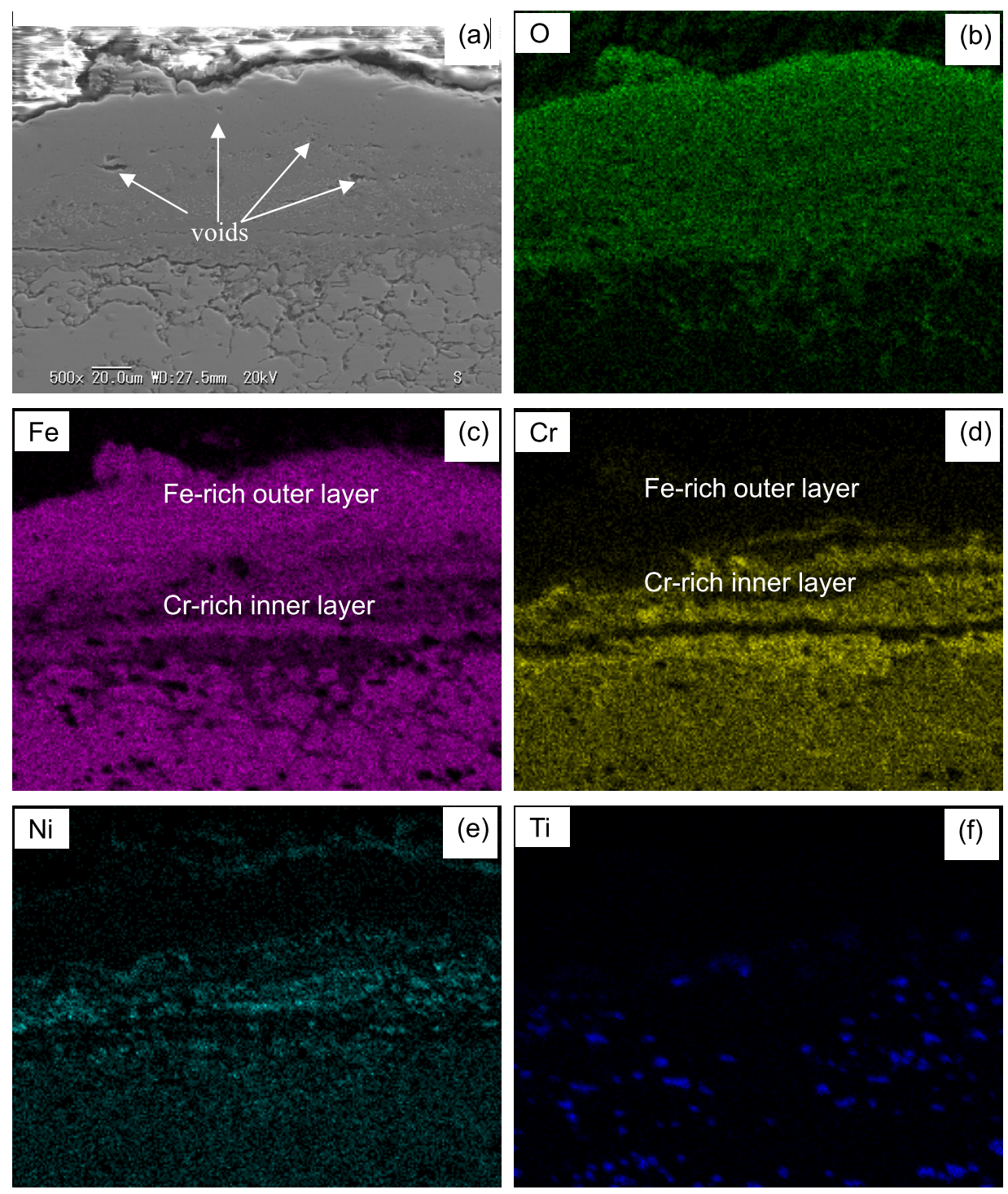

Fig. 7. SEM map-scanning of 304SS-6TiC in simulated marine environment: (a) SEM morphology; (b) O; (c) Fe; (d) Cr; (e) Ni; (f) Ti. (Online version in color.)

$\mathrm{NaCl}$ solutions for $1 \mathrm{~h}$ at room temperature. At $650^{\circ} \mathrm{C}$ for $10 \mathrm{~h}$ in the furnace, the small amount of water in the salt would be rapidly evaporated and the solid $\mathrm{NaCl}$ would deposit on the sample surface. At the first cycle, the corrosion behaviour had been mainly affected by $\mathrm{NaCl}$, not water vapor because the amount of water on the smooth surfaces of samples was slight. For the following cycles, more water would be reserved in the corrosion layer when emerging in 3.5 wt. $\% \mathrm{NaCl}$ solution accompanying the growing porous corrosion layer, and then the effect of water vapor could not be ignored in the following cycles. Large number of studies indicate that the presence of water vapor and $\mathrm{NaCl}$ have a dramatic effect on oxidation behaviour of chromia-forming alloys at high temperature as compared with the dry condition without $\mathrm{NaCl}$.

Many previous papers have reported the oxidation of the stainless steels in solid $\mathrm{NaCl}$ and/or water vapor environments. ${ }^{5-13)} \mathrm{Cr}_{2} \mathrm{O}_{3}$ could first form on the surface of 304SS at $650^{\circ} \mathrm{C}$ in the furnace due to the selective oxidation. However, chemical reactions between $\mathrm{Cr}_{2} \mathrm{O}_{3}$ and $\mathrm{NaCl} /$ water vapor occurred shortly after $\mathrm{Cr}_{2} \mathrm{O}_{3}$ preliminarily formed, resulting in the formation of incompleted $\mathrm{Cr}_{2} \mathrm{O}_{3}$ layer on the surface.

$$
\begin{gathered}
4 \mathrm{NaCl}_{(S)}+2 \mathrm{H}_{2} \mathrm{O}_{(g)}+\mathrm{Cr}_{2} \mathrm{O}_{3(S)}+\frac{3}{2} \mathrm{O}_{2(g)} \ldots \ldots \ldots . . . \\
=2 \mathrm{Na}_{2} \mathrm{CrO}_{4(S)}+4 \mathrm{HCl}_{(g)}{ }^{7)} \\
2 \mathrm{NaCl}_{(S)}+\frac{1}{2} \mathrm{Cr}_{2} \mathrm{O}_{3(S)}+\frac{5}{4} \mathrm{O}_{2(g)}=\mathrm{Na}_{2} \mathrm{CrO}_{4(S)}+\mathrm{Cl}_{2(g)}{ }^{7)} \ldots \\
2 \mathrm{NaCl}_{(S)}+\mathrm{Cr}_{2} \mathrm{O}_{3(S)}+2 \mathrm{O}_{2(g)}=\mathrm{Na}_{2} \mathrm{Cr}_{2} \mathrm{O}_{7(g)}+\mathrm{Cl}_{2(g)}{ }^{3)} \ldots . .
\end{gathered}
$$

The $\mathrm{HCl}$ and $\mathrm{Cl}_{2}$ would inwardly diffuse and reacted with $\mathrm{Fe}, \mathrm{Cr}$ and $\mathrm{Ni}$ in the substrate to form $\mathrm{FeCl}_{2}, \mathrm{CrCl}_{3}$ and $\mathrm{NiCl}_{2}$ which would then evaporate due to relatively high vapor pressures. ${ }^{19,22)}$ They would outwardly diffuse and reacted with $\mathrm{O}_{2}$ which inwardly diffused to form $\mathrm{Fe}_{2} \mathrm{O}_{3}$, $\mathrm{Cr}_{2} \mathrm{O}_{3}$ and $\mathrm{NiO}$.

Moreover, the $\mathrm{Cr}_{2} \mathrm{O}_{3}$ would continue to react with unreacted $\mathrm{NaCl}$ on the surface. The fast reaction between $\mathrm{NaCl}$ and $\mathrm{Cr}_{2} \mathrm{O}_{3}$ would destroy the protective $\mathrm{Cr}_{2} \mathrm{O}_{3}$ layer, leaving behind a Fe-rich oxide with relatively poor protective ability. The Fe-rich oxide layer formed on the surface would be 
very porous due to the evaporation of water vapor, $\mathrm{FeCl}_{2}$, $\mathrm{CrCl}_{3}$ and $\mathrm{NiCl}_{2}$ and the diffusion of $\mathrm{HCl}$ and $\mathrm{Cl}_{2}$. In addition, the evaporation of $\mathrm{Na}_{2} \mathrm{Cr}_{2} \mathrm{O}_{7}$ was possible occurred in this case due to relatively high vapor pressure, ${ }^{3,23,24)}$ resulting in no detection of them in XRD analysis. $\mathrm{Na}_{2} \mathrm{CrO}_{4}$ was not detected in XRD analysis, possibly due to the low volume fraction. In simulated marine environment, $\mathrm{NaCl}$ and water vapor destroyed the protective $\mathrm{Cr}_{2} \mathrm{O}_{3}$ layer, and a thick corrosion scale was formed on the surface of samples.

The intergranular oxidation of the $304 \mathrm{SS}$ in a simulated marine environment was more severe than that in air, as shown in Fig. 6. This was mainly because many holes in the corrosion layer were formed due to the volatilization of $\mathrm{Na}_{2} \mathrm{Cr}_{2} \mathrm{O}_{7}$, water vapor or other chlorides, which provided channels for $\mathrm{O}_{2}$ diffusion. $\mathrm{Cr}$ diffused to the surface and formed a protective scale during the hot corrosion, leading to $\mathrm{Cr}$ depletion in the matrix. The diffusion coefficient of $\mathrm{Ni}$ was higher than that of $\mathrm{Cr}$ in inner oxides when oxygen is sufficient ${ }^{19,25)}$ due to $\mathrm{Cr}$ depletion and many defeats in the inner layer. So Ni could diffuse to the surface of the inner layer and $\mathrm{O}_{2}$ was also easily diffused into the inner layer through the poor protective outer Fe-rich layer. Figure 6(f) showed that the upper part of the inner layer mainly consisted of $\mathrm{NiO}$ or/and $\mathrm{NiCr}_{2} \mathrm{O}_{4}$ in the corrosion layer. Due to the cyclic corrosion tests, the rapid-changing temperature during cooling and heating caused high thermal stress. The cracks were easily formed during the cyclic corrosion, especially at the interface between the Ni-rich oxides and
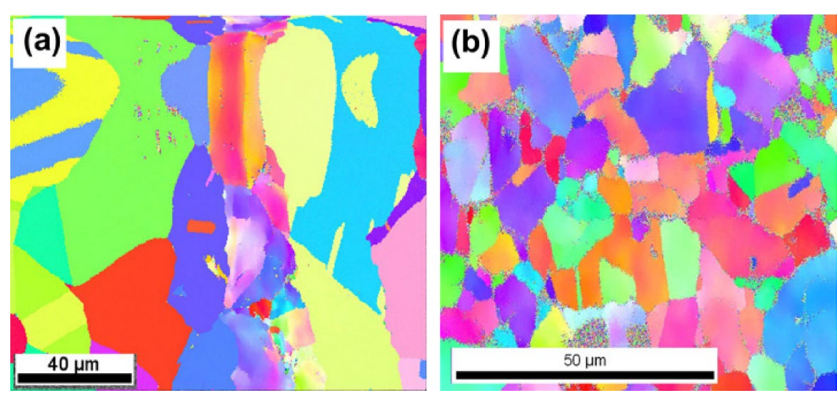

Fig. 8. EBSD area mapping for (a) 304SS and (b) 304SS-2TiC. (Online version in color.) the corrosion layer. This is possible main reason that the cracks in the corrosion layer seem to correspond to the $\mathrm{Ni}$ rich oxides.

\subsection{TiC Addition on Corrosion of 304SS in Simulated Marine Environment}

At $650^{\circ} \mathrm{C}$, chromium diffusion in the steel is mainly dominated by grain boundary transport. Figure 8 shows the grain size of $304 \mathrm{SS}$ and $304 \mathrm{SS}-2 \mathrm{TiC}$ measured by EBSD analysis technology. A much finer structure could be obtained by the addition of TiC into 304SS. In addition, adding TiC to $304 \mathrm{SS}$ also increased the density of dislocation (Fig. 9), which comes from the thermal mismatch strain between the matrix and $\mathrm{TiC}$ after the thermal treatment. Both grain boundary and dislocation provided fast-diffusion paths which increase significantly chromium diffusion. This means that the TiC-304SS had higher capability of forming the protective $\mathrm{Cr}$-rich oxide layers when the breakaway oxidation happened, thus quicker healing ability before extensive damage proceeds.

The reaction between oxygen and $\mathrm{TiC}$ could also occur to produce $\mathrm{CO}_{2}$ and $\mathrm{TiO}_{2}$ during corrosion process at $650^{\circ} \mathrm{C}$ according to following reaction.

$$
\frac{1}{2} \mathrm{TiC}+\mathrm{O}_{2}=\frac{1}{2} \mathrm{TiO}_{2}+\frac{1}{2} \mathrm{CO}_{2}
$$

Meanwhile, EDX analysis also confirmed that the $\mathrm{TiO}_{2}$ was formed in corrosion layer. According to oxidation behaviour of TiC-304SS in air, the fine $\mathrm{TiO}_{2}$ particles dispersed in the scale could act as nucleation sites for chromia formation, thereby accelerating the chromia nucleation and decreasing oxide grain size. ${ }^{16)}$ Fine grain structure of oxide improves scale plasticity, enabling the scale to relieve high stresses and increase oxide scale adherence. ${ }^{26-28)}$ Although the finer grain size of oxide scale formed on TiC-304SS was not observed in simulated marine environment, the formation of $\mathrm{TiO}_{2}$ by the oxidation of $\mathrm{TiC}$ possibly assisted chromia nucleation in this case. In addition, the preexisting $\mathrm{TiO}_{2}$ particles could also play a pegging effect to increase the adhesion of latterly formed chromia scale. Therefore, the addition of $\mathrm{TiC}$ in $304 \mathrm{SS}$ promoted the corrosion resistance
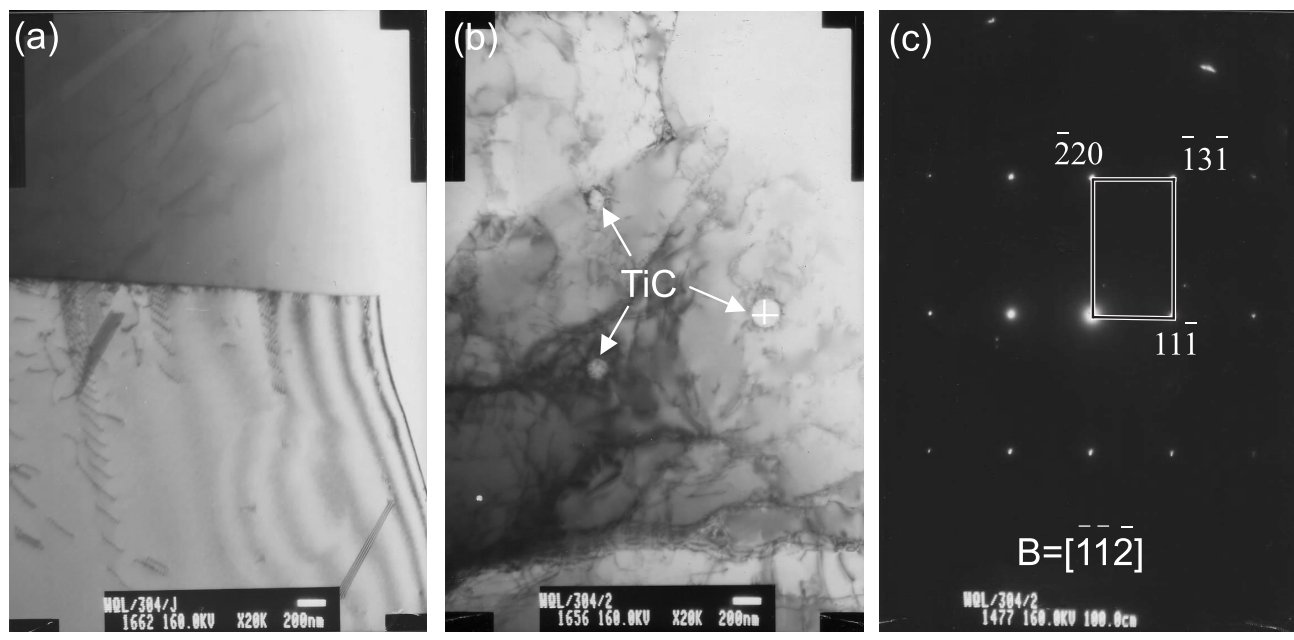

Fig. 9. (a)-(b): TEM bright field image showing the dislocation substructure in 304SS and 304SS-2TiC; (c) selective area diffraction pattern for the marked particle. 
in simulated marine environment.

However, a large amount of $\mathrm{CO}_{2}$ was also released during oxidation process of $\mathrm{TiC}$, leading to the formation of void in the corrosion layer. This was possible main reason that the size of voids in the scale of 304SS-2TiC was smaller than that of 304SS-6TiC. The phase change from $\mathrm{TiC}$ to $\mathrm{TiO}_{2}$ can induce $55 \%$ of volume expansion $\left(\mathrm{V}_{\mathrm{mTiC}}=12.14\right.$, $\left.\mathrm{V}_{\mathrm{mTiO} 2}=18.88\right),{ }^{17)}$ resulting the high stress in the scale. It means that the more spalling occurred for 304SS-6TiC than that for $304 \mathrm{SS}-2 \mathrm{TiC}$ due to the relatively high inhomogeneous stress accumulated in some local regions with increasing corrosion time. Therefore, the above explanation was consistent with the experimental measurement of higher rate of oxidation for $6 \% \mathrm{TiC}$ than for $2 \% \mathrm{TiC}$ steels after 10 cycles.

In addition, with the introduction of $\mathrm{TiC}$ into 304SS, $\mathrm{Cr}$ depletion would be accelerated by the formation of Cr-rich carbide inside the microstructure (see Fig. 2(b)), which resulted in the deterioration of the oxidation resistance of TiC-304SS. However, for TiC-304SS in this work, chromium diffusion played a dominant role on oxidation resistance compared with $\mathrm{Cr}$ depletion in the microstructure.

\section{Conclusions}

In the presence of $\mathrm{NaCl}$ salt and water vapor, the corrosion of $304 \mathrm{SS}$ at $650{ }^{\circ} \mathrm{C}$ was more severe than that in air only. 304SS behaved protectively in air, but suffered breakaway corrosion and a significant spallation in simulated marine environment during the whole reaction time. A much finer structure and higher dislocation density could be obtained by the addition of $\mathrm{TiC}$ into $304 \mathrm{SS}$, resulting in the increase of chromium diffusion in 304SS. Also the oxidation of $\mathrm{TiC}$ into $\mathrm{TiO}_{2}$ on the surface possibly accelerate chromia nucleation and increase the adhesion of chromia scale through pre-existing $\mathrm{TiO}_{2}$ pegging effect. Therefore, $\mathrm{TiC}$ addition promoted the formation of protective $\mathrm{Cr}$-rich layer and greatly retarded breakaway oxidation, leading to the smaller mass gain and oxide scale thickness. However, a large amount of $\mathrm{CO}_{2}$ was also released during oxidation process of $\mathrm{TiC}$, leading to the formation of void in the corrosion layer. Meanwhile, the phase change from $\mathrm{TiC}$ to $\mathrm{TiO}_{2}$ could induce $55 \%$ of volume expansion, resulting in the high stress in the scale. Thus the more spalling occurred for $304 \mathrm{SS}-6 \mathrm{TiC}$ as comparison with $304 \mathrm{SS}-2 \mathrm{TiC}$ due to the relatively high inhomogeneous stress accumulated in some local regions with the increasing corrosion time.

\section{Acknowledgement}

This research was supported by Nation key R \& D program of china (No. 2016YFB0300700, 2016YFB0300704) and by Shanghai Municipal Natural Science Foundation (No. 16ZR1414900).

\section{REFERENCES}

1) L. Liu, L. Ying and F. Wang: Sci. China Technol. Sci., 55 (2012), 369

2) C. Ciszak, I. Popa, J. Brossard, D. Monceau and S. Chevalier: Corros. Sci., 110 (2016), 91.

3) V. Mannava, A. S. Rao, N. Paulose, M. Kamaraj and R. S. Kottada: Corros. Sci., 105 (2016), 109.

4) K. Bawane, K. Ning and K. Lu: Corros. Sci., 131 (2018), 365.

5) L. L. Wei, L. Q. Chen, M. Y. Ma, H. L. Liu and R. D. K. Misra: Mater. Chem. Phys., 205 (2018), 508.

6) Y. Tang, L. Liu, Y. Li and F. Wang: Electrochem. Commun., 12 (2010), 191

7) F. Wang and Y. Shu: Oxid. Met., 59 (2003), 201.

8) Y. Tang, L. Liu, Y. Li and F. Wang: J. Electrochem. Soc., 158 (2011), C237.

9) Y. Shu, F. Wang and W. Wu: Oxid. Met., 51 (1999), 97.

10) Y. Shu, F. Wang and W. Wu: Oxid. Met., 52 (1999), 463.

11) F. Wang: Oxid. Met., 48 (1997), 247.

12) F. Wang, S. Geng and S. Zhu: Oxid. Met., 58 (2002), 185.

13) C. Yu, S. Zhu, D. Wei and F. Wang: Surf. Coat. Technol., 201 (2007), 7530 .

14) Q. Wu, N. Zhong, B. Liu, C. Fan, W. Li and Y. Yin: Corros. Eng. Sci. Technol., 51 (2016), 136.

15) Q. Wu, N. Zhong and W. Li: Corros. Sci., 53 (2011), 4258.

16) Q. Wu, J. Zhang and Y. Sun: Corros. Sci., 52 (2010), 1003.

17) S. Cho, I. Jo, H. Kim, H. Kwon and S. Lee: Appl. Surf. Sci., 415 (2017), 155.

18) M. Cao, L. Liu, Z. Yu, L. Fan, L. Ying and F. Wang: Corros. Sci. 133 (2018), 165

19) L. Chen, H. Lan, C. Huang, B. Yang, L. Du and W. Zhang: Eng. Fail. Anal., 79 (2017), 245.

20) R. Aadhavan and K. Suresh Babu: Surf. Coat. Technol., 272 (2015), 395.

21) J. Zhang, X. Peng, D. J. Young and F. Wang: Surf. Coat. Technol., 217 (2013), 162

22) L. Liu, Y. Li, C. Zeng and F. Wang: Electrochim. Acta, 51 (2006), 4736.

23) C. C. Tsaur, J. C. Rock, C. J. Wang and Y. H. Su: Mater. Chem. Phys., 89 (2005), 445.

24) R. A. Rapp: Corros. Sci., 44 (2002), 209.

$25)$ C. S. Giggins and F. Pettit: J. Electrochem. Soc., 118 (1971), 1782

26) S. A. Kekare, J. B. Toney and P. B. Aswath: Metall. Mater. Trans. A, 26 (1995), 1835.

27) W. Gao, Z. Li and D. Zhang: Oxid. Met., 57 (2002), 99.

28) B. G. Velasco and P. B. Aswath: J. Mater. Sci., 33 (1998), 2203. 